\title{
Research on Low Carbon Construction and Creative Development in Rural Tourism Development
}

\author{
Zhenbang Sun ${ }^{1}$, Deping Zhao ${ }^{2}$ \\ ${ }^{1}$ Shenyang Jianzhu University, School of Architecture and Planning, Shenyang 110168, China; \\ ${ }^{2}$ Shenyang Jianzhu University, School of Science, Shenyang 11016, China.
}

Keywords: Beautiful countryside, low carbon rural area, creative development, rural tourism.

\begin{abstract}
Rural tourism becomes an important force in stimulating local economic development as the core content of the socialism new rural construction under current economic environment. In recent years, single entertainment mode and extensive operation management hinder its further development. How to reflect local culture, improve the management mechanism and carry out creative development at the same time are problems in rural tourism development. Low carbon rural development is combined with rural tourism for protecting environment-energy on the one hand, rural tourism business model is also supplemented on the other hand, and a convenient and low carbon efficient production-life complex space can be constructed, which integrates multiple functions. Low carbon development of rural tourism includes rural energy saving creativity, rural construction creativity, rural environmental protection creativity, rural landscape creativity, tourism activity creativity, etc. New attractions can be derived, and new vitality can be given to rural tourism.
\end{abstract}

\section{Introduction}

Rural tourism is an outing tourism type based on rural communities as activity venues, wherein tourists enjoy rural unique cultural landscape and life styles as the object system. City becomes a rendezvous with high energy consumption, a rendezvous with waste discharge and a rendezvous with ecological reconstruction with the progress of the society, aggregation of human production activities, constant development and updating of industrialization and marketization. When urban modern humans living in reinforced concrete jungles feel tired on crowded and noisy city landscape resorts, rural tourism has become a new fashion of people during leisure vacation and returning to nature [1]. Rural tourism can make people away from noisy crowds. People can feel natural characters and relax themselves in mind and body.

\section{Objectives of Low Carbon Rural Construction}

\subsection{Foreign Rural Tourism}

Foreign rural tourism was proposed in Europe in the 1850s, but the truly popular rural tourism was originated in Spain in the 1960s. Urban residents began to yearn for and pursue peaceful rural life and excellent natural environment in countryside due to acceleration of industrialization and urbanization progress, intense competition of market economy. Spanish government transformed abandoned nobles castles into simple farmhouse, and also listed larger farms into the scope for tourists during tourism and visit, and tourists willing to visit countryside were received under the drive of market demands, therefore rural tourism arose at the historic moment. However, there were fewer rural tourists during the period. The rural tourism facilities for serving tourists especially in true meaning were not available, therefore rural tourism was still in the early stages of development. The accessibility was improved in urban and rural areas due to rapid development of railway and other transportation facilities in the 1970s; the accessibility of tourists was enhanced, thereby prompting extensive development of rural tourism in many countries. Strong vitality and development potential [2] were displayed. Global green movement was started in the 1980s, thereby promoting rapid development of rural tourism. It became one of important choices of modern tourists in European and American developed countries. Rural 
tourism became an important part of ecological tourism in the 1990s. Rural tourism began to expand from developed countries to developing countries under vigorous promotion and encouragement of world tourism organization. It has become an important means to promote local economy [3, 4].

\subsection{Domestic Rural Tourism}

Most domestic scholars believe that rural tourism was started in China since the 1980s [5]. It is mainly determined by demand and supply in the tourism market during the period. First of all, acceleration of urbanization progress makes people approach to nature, the desire of relieving urban pressure is increasing, rapid development of economy urges people to allocate income, and the leisure time is gradually increased from the point of view of market demand. Postmodernism lifestyle fully penetrated into people's daily life. More and more people pursue tradition and desire freedom. The rural tourism returning to the nature can meet those needs of people. Secondly, China rural industrial structure should be adjusted since the 1980s from supply perspective. Then, how to develop rural economy and increase farmers' income have become problems that must be encountered by governments in rural areas. Domestic governments at all levels regard tourism as an effective means of promoting rural economic recovery according to development experience of rural areas in foreign developed countries, and they commit to plan and develop different rural tourism projects $[4,5]$.

Rural tourism is still in the initial stage as a whole after 1990. Rural tourism products are mainly based on 'sightseeing farm scenery, tasting farmhouse meal, participating in farm work and enjoying countryside pleasure'. Scenic spot dependence development mode is always adopted for the developed rural tourism destinations, which are mostly distributed in outskirts of major cities, characteristic agriculture areas and eastern developed areas. National Tourism Administration launched tourism year with rural tourism as the theme for four times successively from 1998 to 2006, thereby pushing China rural tourism to a new peak. The rural tourism wave is started across the country. More than 20000 rural tourism resorts (scenic spots) have been constructed in China as of 2006, including 359 'national agricultural tourism demonstration pilots', which are distributed in 31 provinces and municipalities. Tourists received by rural tourism resorts (scenic spots) were up to more than 300 million person-times all over the country in 2006 alone, and the tourism revenue was more than 40 billion Yuan. National Tourism Administration launched the national leisure plan in 2008. Rural leisure was regarded as an important part of national leisure. Rural tourism has entered a new stage of comprehensive development under the joint drive of governments and competent departments all levels [5].

\subsection{Construction Goal of Low-Carbon Rural Areas}

Rural low carbonization indeed refers that regional resources are used intensively, energy is saved, and emission of carbon dioxide and various wastes is reduced during socialist new rural construction (including rural tourism development). Rural resident environment can become beautiful actually, income is increased, and their life becomes happier. Rural low carbonization can be divided into follows according to contents: rural building low carbonization, rural traffic low carbonization, rural energy low carbonization, rural life low carbonization, rural environment low carbonization and rural society low carbonization. Low carbon rural construction actually refers to construction of a convenient, low-carbon and efficient production-living complex space, which integrates many functions. It becomes a low-carbon rural complex supported by development of modern agriculture, agricultural product processing, rural tourism and other intensive clusters.

'Resource-conserving and environmental-friendly' community construction continuously spreads to rural area with the deepening of national policy implementation of scientific development concepts in China. Low carbon rural construction also spreads out all over the country with excellent results, such as: low-carbon farming preparation in Hengyang of Hunan; 'mulberry-grass-herd -bog' circular economy mode implemented in Yibin County of Sichuan Province; production of novel biomass fuels by corn stalks in Huguan County, Shanxi, etc., which are becoming new fashions of local farming culture gradually. Ecological agriculture system (i.e. low carbon agricultural mode) can offset about $80 \%$ of global greenhouse gas emission caused by agriculture (such as carbon dioxide); domestic cooking energy consumption in rural area as well as domestic electricity consumption and domestic hot water demand in rural areas can be satisfied by comprehensive utilization of straw, livestock and 
poultry dung, solar and other renewable energies. Reduction of fertilizer consumption also can promote the development of eco-organic agriculture.

\subsection{Problems in Rural Tourism}

Research and practice of rural tourism at home and abroad are combined. Current rural tourism in China has the following problems: management mechanism is not sound, the government function is not fully exerted, corresponding policies and regulations as well as overall planning and control are insufficient; The understanding on rural tourism is limited. People's consciousness is limited in the traditional stage of 'dressing and wearing'. The negative, disorderly and blind development leads to intensifying negative influence; infrastructure construction is inadequate; product serialization and depth are not sufficient.

\section{Low Carbon Design in Tourism Creativity}

Low-carbon economy has become a social trend, a technological revolution and a lifestyle. Low-carbon development of rural tourism actually belongs to culture innovation of a new round. Development of vanilla farm tourism in Huairou of Beijing is adopted as an example. The creative theme is 'flower rain in the sky and happy rural life'. The creativity propaganda is 'the most beautiful vanilla sea in Beijing'. The creative landscape is rural landscape scenery and European architectural complex during Italian Renaissance'. The creative content is 'establishment of a happy farm, fostering of a land, cultivation of green plants, and harvesting of happiness'. People can spend spare time to act as farmers and landlords, and participate in weeding, fertilizer application and harvesting in the farm like a computer game.

Low carbon economic background gives more versatility to creative agriculture. Agricultural versatility is an objective attribute of agriculture and its development. Agricultural production and operation activities are important activities for economic and social development of human beings. The natural feature of agricultural production and operation is combined with its social feature to form agricultural versatility. Agriculture has different functions in different stages of development. Meanwhile, agriculture functions are also changed with different economic, social and culture development levels in own regions. Production and ecological functions are common functions of agriculture in all ages and regions. New patterns are produced constantly in global agriculture with the development of economy and society, and versatility is presented gradually. Versatility construction of agriculture is an important trend of world agriculture development.

\section{Creative Design in Low Carbon Rural Tourism}

The creative design of low carbon rural tourism is reflected in various aspects: architecture, environmental protection, landscape, etc. Concrete contents are shown as follows:

\subsection{Rural Energy Saving Creativity}

It includes creative design of energy-saving lamps and lanterns, creative construction of bio-digester, creative use of waste combustion, creative development of solar energy and wind utilization, creative construction of energy-saving hearth, etc.

\subsection{Creativity of Rural Architecture}

Transformation and utilization of the farmhouse are focal points during construction of rural tourism. How to make use of the local cultural characteristics and the characteristics of vernacular architectures should be considered seriously. For example, local topography characteristics should be considered for architectural style and model in a development zone of China rural tourism, all elements should be integrated, external walls and window panes can be coated into coffee uniformly, melon vine frames or grape vine frames can be erected, a small yard can be formed by straws and crop stalks. The house direction is planned to sun uniformly. Neighboring building styles should be consistent. Rural graffiti also should be designed on the wall, etc.; Dutch architect-Studio Macklin designed ' 'balance barn' which is hung on both ends and erected on the road in the middle. A layer of reflector is covered outside the building, thereby giving people a different feeling. Danba is known as 'the most beautiful 
village in China' due to its unique folk creative ancient architecture and natural environment. In addition, the construction industry is a high-carbon industry; therefore the usage of cement and steel should be saved as far as possible.

\subsection{3 Creativity of Rural Environmental Protection}

It includes creative design of low-carbon transportation, creative design of garbage patch, creative design of domestic sewage and solid waste discharge, creative design of garbage sorting and processing, creative use of new fertilizers, creative development of novel pesticides, etc.

\subsection{Rural Landscape Creativity}

It includes garden creative design, creative design of country clubs, pastoral scenery creative design, creative collocation of tree nursery, creative design of flower pots, creative design of road building aqueducts, creative design of low-carbon farming restaurants, creative design of landscape bar, etc.

\subsection{Creativity of Tourism Activities}

It includes creative design of rural song and dance, creative design of folk customs, creative design of tourist lines, creative design of tourism products, creative design of tourist clothing, creative development of tourism programs, etc.

\section{Conclusion}

We should seek village soul on the one hand, and focus on low carbon economy on the other hand during creative development of low carbon rural tourism. We should keep pace with international concepts and rely on innovative new resources. Currently, all cities and regions pay much attention to catering entertainment; however rural culture is explored and utilized insufficiently. Culture is the soul of tourism. It is necessary to explore 'three-agriculture' culture tourism resources, create rural amorous feelings, carry forward farming culture, inherit national culture heritage, rural areas are created to be more and more rural. Tourists can appreciate waters and mountains, and remember feeling of hometown, thereby creating an ideal Peach Garden, which is composed of flat land, tall building, high-quality farmland, beautiful pools and bamboos.

\section{Acknowledgements}

This research was financially supported by The Project of Social science planning fund of Liaoning: Research on the construction and transmission of rural cultural industry in Northwest Liaoning based on innovation driven (No. L15BGL019).

\section{References}

[1]. Fang Liang. Overview of research on development and construction of rural tourism. Journal of Jilin Normal University ( Humanities and Social Sciences Edition) 2013, 41(6):69-71;

[2]. Su Beichun. New growth points of rural tourism - agricultural economy. Township Economy, 2007(4):24-26.

[3]. Dong Zhiwen, Zhang Ping. Overview of research hotspots of China rural tourism in recent years. Journal of Anhui Agriculture, 2009(5):2149-2151.

[4]. Wang Qiongying, Feng Xuegang. Review of rural tourism research. Journal ofBeijing International Studies University, 2006(1):115-119.

[5]. Zhang Shumin, Zhong Linsheng, Wang Ling'en. Discussion of China rural tourism development model based on theory of tourism system. Geography Research, 2012(11):2094-2103.

[6]. Liu Xiao. On low carbon economy and low carbon tourism. China Collective Economy, 2009(13):154-155. 